Revista de Indias, 1996, vol. LVI, núm. 206

\title{
LA VISITA DE 1776 A LAS PARROQUIAS PAMPANGAS DE FILIPINAS
}

POR

MARTA MARÍA MANCHADO LÓPEZ

Universidad de Córdoba

Este trabajo se centra en el estudio de la situación de las veintidós parroquias de la provincia filipina de la Pampanga, a través de la visita pastoral realizada por el arzobispo de Manila en el año 1776. Se trata de la primera inspección episcopal realizada en estas parroquias, que habian sido violentamente secularizadas cinco años antes.

Este estudio se ha realizado sobre documentación inédita del Archivo General de Indias, e incide especialmente en la situación de las iglesias, la labor del clero que las servía y el grado de evangelización de los naturales.

La primera inspección realizada por un diocesano de las veintidós parroquias de la provincia filipina de la Pampanga tuvo lugar en el año 1776, cinco años después de que fueran secularizadas (1). Efectivamente, con anterioridad a esta fecha,

(1) La provincia de la Pampanga está situada al Norte de Manila, en el centro de la isla de Luzón. Era alcaldía mayor y en la época estudiada contaba con veintidos pueblos. Su cabecera era el pueblo de Bacolor. Esta visita fue realizada por el metropolitano de las islas, don Basilio Sancho de Santa Justa y Rufina, quien ocupó la mitra de Manila de 1767 a 1787. Sobre su pontificado véase mi estudio Conflictos Iglesia-Estado en el Extremo Oriente Ibérico, Servicio de Publicaciones de la Universidad de Murcia (en prensa). 
los ministerios pampangos estaban confiados a los agustinos calzados, a quienes les fueron arrebatados en un proceso secularizador que levantó ampollas en las islas y fue censurado en la Corte (2).

El expediente relativo a esta visita es sumamente interesante por los datos que proporciona sobre el estado de dicha provincia filipina, pero su estudio no puede realizarse sino desde la perspectiva de las particulares circunstancias que concurrían en ese momento y que muy probablemente llevaron al arzobispo a presentar una imagen interesada de la situación en las parroquias pampangas.

La visita supuso, por otra parte, la introducción de reformas que venían a completar la transformación de la provincia tras la secularización de las parroquias. Desde esta perspectiva, supone la culminación del proceso abierto tras la salida de los doctrineros regulares, ya que se suprimieron las Cofradías de la Correa, siendo sustituidas por otras, y se redistribuyeron algunos de sus bienes para garantizar la subsistencia de las parroquias.

Pero no fue ésta la única novedad introducida por el metropolitano. El arzobispo procedió a la división de la provincia, en lo relativo al gobierno espiritual, en dos presidencias. La gran extensión de la Pampanga aconsejaba realizar esta división y al frente de cada una de las circunscripciones se colocó a un sacerdote, con título de "Presidente». Estos cargos recayeron en los párrocos de México, el religioso agustino Fray Manuel Serradel, y el de Minalín, Dr. don Manuel Francisco Tubil.

Su misión era vigilar la vida y costumbres de los curas, convocarlos a reuniones dos veces al mes, examinarles tres veces al año de las materias relativas a sacramentos y a conciencia, y dar cuenta mensualmente de cuanto observaran en el comportamiento de dichos curas. Con relación a este último punto, los presidentes tenían que informar al arzobispo de la forma en que se conducían en sus respectivos ministerios, de su vida y costumbres y del trato que deban a sus feligreses.

(2) Sobre el proceso de secularización de las parroquias pampangas, véase mi estudio "Las doctrinas agustinas de la Pampanga (1771-1774)», en Archivo Agustiniano, vols. LXXIV, LXXV y LXXVI, núms. 192, 193, 194, Zamora, 1990, 1991 y 1992, págs. 323-388, 285-358 y 73-102.

R. I., 1996, n.o 206 
La elección de los Presidentes obedeció al deseo de colocar en este puesto al sacerdote con una formación más amplia (el párroco de Minalín era el único que poseía el grado de doctor), y a un religioso, ya que habiendo cuatro agustinos en la Pampanga, la supervisión de su actividad y comportamiento por quien en definitiva era su hermano de hábito no despertaría suspicacias, a las que eran muy susceptibles los regulares.

Es evidente que a esta medida subyace un gran interés por controlar la actividad de los párrocos, lo cual se explica por el celo que siempre demostró el arzobispo Sancho. Pero no hay que olvidar, y sobre este tema volveré más adelante, que el clero secular, y en especial el colocado en la Pampanga, fue durísimamente criticado, tachándosele de indigno, ignorante $\mathrm{e}$ incapaz. Estas críticas eran conocidas en la Corte, donde las Ordenes Religiosas y algunas importantes autoridades civiles habían hecho ver que la secularización de las parroquias en Filipinas era un despropósito que conducía inexorablemente a la pérdida de esas cristiandades. Es por esto fácil de comprender que el arzobispo de Manila, defensor de las secularizaciones y del clero secular indígena, quisiera sumar a sus elogios la garantía de que la actividad de los nuevos párrocos sería supervisada muy de cerca. Esto tranquilizaría su conciencia y acabaría con las suspicacias del monarca y sus ministros.

\section{El DESARRollo DE La Visita. LAS PARRoQuias Visitadas}

La visita fue iniciada el 8 de enero de 1776, a las cinco y media de la mañana, y se desarrollo a lo largo de este mes y del siguiente. Realizada en persona por el metropolitano, a pesar de su "quebrantada salud», comenzó por el pueblo de Mecabebe y concluyó el 15 de febrero por la tarde en Apalit (3).

(3) El testimonio completo de los autos de la visita a las parroquias pampangas realizada por el arzobispo de Manila se encuentra en AGI, Filipinas, 653. Fue remitido al Consejo en cumplimiento de las Reales Cédulas de 22 de junio de 1778 y 29 de febrero de 1776, acompañados de Carta del arzobispo fechada en Manila, a 20 de diciembre de 1779. Previametne había remitido testimonio de lo obrado en la citada visita con carta de 23 de julio de 1776. Para diferenciar ambos expedientes, en lo sucesivo aludiré a ellos citándolos como «Testimonio» y "Testimonio completo». 
Las dificultades que hubo de arrostrar el arzobispo en su marcha de un pueblo a otro quedan reflejadas en la documentación. Así, se indica que el desplazamiento entre Gapán y Sạntor le ocupó un día solar "por caminos fragosos y por montes", y que el viaje desde Gapán a Candava, realizado por río, le llevó «bien fatigado» a este pueblo tras una dura jornada (4).

Los penosos desplazamientos por tierra y ríos le hicieron enfermar «de resfriado y calentura» en el pueblo de México, aunque no por eso suspendió la visita (5). Esta se desarrolló sin ningún otro contratiempo, tanto en las parroquias servidas por curas, como en las confiadas a clérigos regulares, lo que era de esperar ya que los cuatro agustinos calzados que administraban los pueblos de San Fernando, México, Santa Ana y San Luis habían acatado públicamente la Visita Diocesana.

Las iglesias de la Pampanga, levantadas por los agustinos calzados, habían sido construidas con materiales variados; 12 de ellas eran sólidos edificios de piedra (combinada con ladrillo en algunos casos) y con una cubierta de tejas o de pajas y caña. Las demás iglesias eran edificios más humildes realizados en madera, cañas y pajas.

Sin embargo, aun las más sólidas se encontraban con frecuencia «maltratadas» y requerían reparaciones que en algunos casos debían acometerse con urgencia. Los repetidos terremotos (el último tuvo lugar el año 71), causaban enormes destrozos. Tal es el caso de la iglesia de la cabecera de la provincia, Bacolor, en la que era necesario celebrar los oficios en el crucero, "porque del crucero para la parte mayor está totalmente sin techado y las paredes rajadas por varias partes» (6). La situación de deterioro del edificio era tal que el arzobispo dispuso, además de su inmediata reparación, que en adelante se celebraran los divinos oficios en la visita de San Vicente, "que es toda de manera fuerte y bastante decente para el efecto, y aun para depositar en ella el Divinísimo Sacramento» (7).

En general aquellas de apariencia más sólida eran las que se encontraban en peores condiciones. Lo costoso de las repara-

(4) Testimonio, AGI, Filipinas, 653 , fol. $14 \mathrm{v}$ y $17 \mathrm{v}$.

(5) Ibidem, fol. $11 \mathrm{v}$.

(6) Ibidem, fol. $9 \mathrm{v}$.

(7) Ibidem.

R. I., 1996, n.o 206 
ciones y la frecuencia con que habían de realizarse estas, hacían que el mantenimiento de los templos con la necesaria decencia fuera difícil. Con todo, en el expediente queda constancia del interés del diocesano en que se emprendieran las necesarias obras, y de los desvelos de algunos curas que aplicaban a esta tarea incluso sus pequeños ingresos. Así, en Palusapis el cura había levantado un nuevo templo con las limosnas que fue recogiendo. El edificio, a decir de los documentos, era "de hechura exquisita, bien que con materiales de madera toda, cubierta de nipa, con su zaquizami de tabla» (8).

En otros casos, las obras habían quedado detenidas, por falta de dinero, como en Arayat, cuyo templo estaba sin terminar. El estado ruinoso de la parroquia del pueblo de Santa Rita, llevó a los fieles a solicitar al arzobispo la construcción de un templo nuevo en el mismo emplazamiento. Los naturales del pueblo se ofrecían a correr con los gastos de construcción y mantenimiento, a cambio de que en adelante se les eximiese del pago de derechos de sepultura, petición que fue concedida por el arzobispo. Lo mismo solicitaron, y obtuvieron, los naturales y mestizos del pueblo de San Fernando.

La necesidad de hacer frente a las periódicas reparaciones exigía un gran esfuerzo de los curas que tenían que reunir los materiales necesarios y el dinero para costear las reformas. En este punto, algunos párrocos dan muestras no sólo de sus desvelos, sino de una administración de los fondos parroquiales digna de encomio. Este es el caso del párroco de Candava quien había reparado su templo consiguiendo que quedara remanente de dinero.

También en los documentos queda constancia de la generosidad de los ministros; ejemplo de ello era fray Mariano Alafont, que había reparado a su costa la iglesia del pueblo de Santa Ana invirtiendo en ello algo más de 92 pesos, cantidad que había donado.

Las iglesias, aunque necesitadas de reparaciones, reunían en general condiciones para el culto divino y para contener el sagrario. Solamente la de San Fernando y la de San Luis no guardaban el Santísimo Sacramento.

(8) Ibidem, folio 16. 
Tres años más tarde, el arzobispo informó al rey del fin de las tareas de reconstrucción de las iglesias de Bacolor, Candava, Santa Rita, Palusapis, Macabebe, Betis y Minalín y de la continuación de las obras de restauración en otras parroquias, realizándose todas ellas sin causar gasto al real erario, ni a los fieles (9).

En general las iglesias contaban con ornamentos y objetos de culto suficientes, aunque frecuentemente muy usados. En el caso de la de San Fernando, los documentos reconocen que el número de ornamentos y vasos sagrados era escasísimo, y de la iglesia de Santa Rita se explica que era tan pobre que cuando se necesitaban el cura se servía de los de otras iglesias.

El caso contrario es el de los templos de Lubao, Betis, Gapán y Santor, dotados de buenos ornamentos de todos colores, vasos sagrados y alhajas de oro y plata. Caso especial es el de la parroquia de Guagua que poseía alhajas de plata nuevas que había mandado labrar su párroco empleando en ello la mayor parte de su peculio (10).

Fue precisamente la situación de pobreza en que se encontraban las iglesias, sin fondos con que hacer frente a los cuantiosos gastos de las reparaciones y con un ajuar escaso y generalmente deteriorado por el uso, y el poco salario que se entregaba a los maestros, lo que empujó al arzobispo a aplicar en su beneficio parte de las tierras de labor de las Cofradías fundadas por los agustinos.

Efectivamente, en la mayor parte de los pueblos pampangos los agustinos calzados habían fundado cofradías bajo el nombre de Nuestra Señora de la Correa. Algunas de ellas disponían de importantes ingresos procedentes de la explotación de tierras. El arzobispo aprovechó la coyuntura favorable de la secularización de las iglesias pampangas, tras la remoción de los doctrineros agustinos calzados en el año de 1771, para suprimir dichas cofradías y erigir en su lugar la Archicofradía del Santísimo Sacramento y Benditas Animas del Purgatorio,

(9) El arzobispo de Manila al rey, Manila 20 de diciembre de 1779. AGI, Filipinas, 653.

(10) Véanse sobre este particular los detallados inventarios de las veintidós parroquias, incorporados al testimonio completo de los autos de la visita.

R. I., 1996, n. ${ }^{\circ} 206$ 
que se regiría conforme a los estatutos de la erigida en la Catedral de Manila.

El momento de la visita del año 1776 fue aprovechado por el arzobispo para llevar a cabo estas medidas y para aplicar parte de los bienes de las antiguas cofradías agustinas a las iglesias de la provincia. Es importante señalar que el arzobispo fundamenta sus reformas en el hecho de que la secularización de las iglesias agustinas había sido aprobada por el rey, sin embargo es preciso tener en cuenta que el monarca había aprobado la secularización, pero condenado la remoción de los doctrineros agustinos, detalle éste que el arzobispo pasa por alto, dando por concluido un asunto que aún no estaba definitivamente cerrado (11).

Entre las razones aducidas por el metropolitano para proceder a estas reformas se encuentra la «ninguna oposición de las expresadas confradías", cuyos miembros asintieron unánimes a los deseos episcopales (12).

Sin embargo, el Fiscal del Consejo consideró que pese a que el arzobispo poseía facultades para adoptar estas medidas, el Consejo no podía aprobarlas en tanto no le constara que había obrado legalmente. De ahí que se aconsejara que se pidieran informes al gobernador de las islas sobre las causas que habían movido al arzobispo a dictar esas medidas y si de ellas podía derivarse algún perjuicio. El deseo de respetar las exigencias del Real Patronato, en especial en lo referente a la protección de las obras pías, convenció al Fiscal de la necesidad de supeditar la aprobación de lo obrado a un más profundo conocimiento del asunto, y el Consejo fue de este mismo sentir (13).

(11) Reales Cédulas, Madrid, 28 de diciembre de 1773 y San Lorenzo, 9 de noviembre de 1774. la primera se encuentra en AGI, Filipinas 1043 y la segunda en AGI, Filipinas, 1027.

(12) El arzobispo de Manila al rey, Manila, 23 de julio de 1776, AGI, Filipinas, 653.

(13) Vista del Fiscal del Consejo, 14 de mayo de 1778. AGI, Filipinas, 653. El Consejo acordó además pedir al gobernador que remitiera un ejemplar de los estatutos de la Cofradía de la Catedral de Manila que había establecido también para las cofradías reformadas de la Pampanga. Asimismo, debía acompañar voto consultivo de la Audiencia sobre si resultaría algún perjuicio de la persistencia de las medidas introducidas por el metropolitano. Acuerdo del Consejo de Indias, 26 de mayo de 1778. AGI, Filipinas, 653. 
Es fácil suponer que siendo la secularización de las doctrinas pampangas un problema aún no definitivamente resuelto, el Consejo se resistiera a aprobar la reforma de las cofradías agustinas adheridas a dichas iglesias, máxime cuando el rey había dispuesto por Real Cédula de 11 de diciembre de 1776 que se suspendiera la secularización de curatos en Filipinas y que se devolvieran a los religiosos los que habían servido (14).

El auto por el cual el arzobispo instituyó en Macabebe la nueva archicofradía fue repetido literalmente para las demás parroquias de la provincia. En este documento se señalaba además que una parte de las tierras de labor que tenía la antigua cofradía se aplicaría a la fábrica de la iglesia, y así quedaría recogido en escrituras separadas. La administración de estas tierras correría a cargo del párroco, encargado de emplear los réditos para la compra de materiales necesarios para la restauración del templo (15).

No todas las cofradías agustinas disponían de tierras, y aquellas que las tenían poseían extensiones muy variadas, de ahí que la proporción de tierras de labor que les fueron enajenadas resultó muy variable. Así, las cofradías de Minalín, Santa Rita, México, Gapán, Santor, San Miguel de Mayumú, San Simón y Apalit, carecían de tierras. De las que sí poseían tierras, las que tenían en mayor cantidad eran las de los pueblos de Macabebe, Guagua y Betis. En este último se aplicó el rendimiento de unos terrenos para el salario del maestro de niños.

\section{LA POBLACIÓN INDÍGENA}

No disponemos de estudios sobre la población total del archipiélago en esta época, de aquí que no podamos valorar la

(14) Real Cédula, Madrid, 11 de diciembre de 1776, AGI, Filipinas, 1027.

(15) Auto de la creación de la Archicofradía del Santísimo Sacramento del pueblo de Macabebe, Macabebe, 11 de enero de 1776. Está incorporado al Testimonio completo de los autos de la visita. AGI, Filipinas, 653. Este auto se redactó en los mismos términos en todas las parroquias pampangas en las que existían cofradías agustinas: Minalín, Guagua, Betis, Bacolor, Santa Rita, México, Arayat, Gapán, Santor, San Miguel de Mayuḿ, San Simón, Apalit.

R. I., 1996, n.o 206 
situación demográfica de la provincia de la Pampanga en el conjunto de las islas.

No obstante, la documentación de la visita de 1776 proporciona datos interesantes; así, el número de habitantes de la provincia es de 64.053 , de los que la mayor parte corresponde a indios (51.590). Bacolor, cabecera de la provincia, es la localidad más poblada (4.210 indios), y Magalang el pueblo más pequeño (sólo 937). Únicamente en cuatro localidades no se registra presencia de mestizos de chino. Estos aparecen en mayor proporción en los pueblos de Bacolor, San Fernando, México y Gapang, aunque el número total para el conjunto de la provincia es de 11.986 (lo que supone un $18,7 \%$ ). La población europea y mestiza de español es escasísima (477 habitantes, lo que supone un 0,74\%), siendo Bacolor con diferencia la localidad donde aparece concentrado un mayor número de ellos (16).

Según afirma el arzobispo, los naturales de la provincia eran muy dados a los chísmes y aquí se encontraba la causa de sus rencillas y divisiones. Sin embargo, el mayor perjuicio les provenía de su relación con los mestizos de sangley, ya que, siendo estos laboriosos y usureros, y aquellos dados a la desidia y a otros vicios, era muy frecuente que terminaran por quedarse con las tierras de los naturales, que quedaban reducidos a una situación miserable.

El caso extremo se producía cuando los naturales se convertían en inquilinos de los mestizos en las que antes eran sus propias tierras (esto sucedía en el pueblo de San Fernando). A este estado les conducía su inclinación a pleitos [así, el cura de Bacolor afirma que "por un palmo de tierra seguirán demanda, gastando aun lo que no tenían» (17)], también su gusto por la ostentación, como lo denuncia el párraco de Candaba que afirma que esta inclinación era aún mayor en los hombres que en las mujeres. Los préstamos usurarios, la práctica de entregar prendas que eran retenidas y el acaparamiento de productos que después eran vendidos a precios abusivos, actividades

(16) Véase el esquema relativo a los habitantes de la provincia de la Pampanga.

(17) Informe sobre los naturales del pueblo de Bacolor, "Testimonio", AGI, Filipinas, 653, fol. 9. 
desarrolladas por los mestizos de sangley, contribuían asimismo a asumir en la pobreza a los naturales.

Contra todos estos vicios predicó insistentemente el arzobispo en el transcurso de su visita con algún fruto, ya que, a decir del secretario de la visita, en el pueblo de Gapán los mestizos de sangley "comenzaron a buscar el camino seguro de su salvación y algunos restituyeron de pronto algunos logros que consideraron ilícitos y prendas empeñadas a los damnificados protestando públicamente enmendarse en adelante» (18).

Los informes sobre los naturales de los distintos pueblos no son muy negativos, frecuentemente se les define como «quietos, dóciles, pacíficos y humildes", dedicados al cultivo de la tierra, a la explotación de la nipa y a la caza. Sin embargo, el párroco de Lubao asegura que sus feligreses son «inquietos y viciosos» y el de Betis se lamenta de la inquietud que siembra entre sus parroquianos los enredos de un par de bachilleres. El cura de Becolor, por su parte, denuncia la costumbre de sus feligreses de enzarzarse en pleitos alimentados por chismes, y de enredar incluso al propio cura con el alcaldo mayor de la provincia.

Es poco lo que los documentos nos dicen sobre la vida espiritual de los naturales, únicamente el párroco de San Miguel de Mayumú asegura que los naturales son «cavilosos y perezosos en lo espiritual», y que se dedicaban con tanta ansia a la explotación del oro que recogían con abundancia en las riberas de los ríos, y a la explotación del tabaco, que no descansaban ni los días de precepto (19). También el párroco de Palusapis se lamenta de la inclinación de sus feligreses a las rancherías y a la caza, consecuencia de lo cual era la dificultad que se le ofrecía para llevar una correcta asistencia espiritual, aunque, eso sí, reconoce que todos los domingos acudían a la misa y a la doctrina.

Sin embargo, a juicio del arzobispo la situación espiritual de la provincia era buena, como queda patente en las siguientes palabras del prelado:

(18) Informe sobre los naturales del pueblo de Gapán, "Testimonio", AGI, Filipinas, 653, fol. 15

(19) Informe sobre los naturales del pueblo de San Miguel, "Testimonio", AGI, Filipinas, 653, fol. 17v.

R. I., 1996, n. $^{\circ} 206$ 
«El estado de la Religión no tiene decadencia alguna, antes sí aumento, por la aplicación de los curas, quienes, aunque con trabajo y a veces con detrimento del propio honor, procuran reducir al verdadero camino de su salud a los que se desvían por sus vicios» (20).

En realidad, el arzobispo estaba muy interesado en presentar una imagen positiva de la situación de la Pampanga, y de dejar muy claro que la secularización de las parroquias no había supuesto detrimento alguno para la asistencia espiritual de la población. No hay que olvidar las violentas invectivas de los regulares contra esta medida y que se llegó a profetizar la pérdida de esas cristiandades, tras la salida de los agustinos. Por otro lado, es preciso recordar que el asunto no estaba aún cerrado y que la polémica sobre la capacidad y eficacia de los clérigos seculares era muy viva.

Los informes de los párrocos no hacen referencia alguna al uso del castellano, ni a la actitud de los naturales en esta materia. Es el arzobispo el que en carta enviada al rey tres años después de efectuada la visita expone la situación de la provincia.

Efectivamente, asegura que los pampangos se aplicaban al estudio del castellano y mandaban a sus hijos a los colegios de Manila. También afirma que la enseñanza en la lengua pampanga había sido desterrada de las escuelas de toda la provincia, y, en otro documento asegura que en toda la Pampanga baja, la mayor parte de sus naturales habla el castellano.

Un solo mal derivaba de esta evidente mejora y era fruto del temperamento de los propios filipinos: cuando eran capaces de desenvolverse en castellano se envalentonaban y ensoberbecían, enredando a los curas con el alcalde mayor.

Con todo, las palabras del metropolitano resultan sorprendentes si tenemos en cuenta la situación de la provincia tan sólo siete años atrás. Efectivamente, existe constancia de que en 1772, la situación del castellano en la Pampanga no difería mucho de la situación en el resto del archipiélago, es decir, que su difusión era escasísima. Este fenómeno era, además, homogéneo en todos los pueblos de la provincia. Únicamente en Ba-

(20) El arzobispo de Manila al rey, Manila, 20 de diciembre de 1779, AGI, Filipinas, 653. 
color, cabecera de la provincia, el conocimiento del castellano por parte de la población indígena era mayor. Otro pueblo próximo a este, Guagua, presentaba un grado de difusión del castellano algo mayor que en el resto de la provincia, pero aún así eran mayoría quienes desconocían la lengua castellana (21).

En otro orden de cosas, la fuerza con la que habían arraigado en toda la provincia costumbres profanas que desvirtuaban el profundo sentido de la Semana Santa, llevó al arzobispo a redactar, una vez concluida la visita, un auto sobre las procesiones de Semana Santa. En él prohibía taxativamente los convites y comilonas celebrados con motivo de las procesiones, así como el hecho de que permanecieran abiertas tiendas de comidas "que apartan a las almas del fin de la institución de las procesiones». Confiaba a los fiscales celadores de cada localidad, "auxiliados del brazo secular» perseguir estos excesos que serían castigados con la confiscación, en beneficio de los pobres, de la comida. También debían velar por erradicar la práctica, muy extendida, de comerciar los domingos y días de precepto.

La publicación de esta providencia fue encargada a los curas quienes debían además impedir que en las procesiones de Semana Santa desfilaran «centurión, pajes y otras representaciones que nada conducen a la meditación de la pasión de Cristo", y velar por que dichas profesiones concluyeran al anochecer (22).

\section{LOS CURAS PÁRROCOS}

De los 22 sacerdotes que atendían las parroquias pampangas, 18 eran clérigos seculares y cuatro agustinos calzados, a los que la visita sólo afectó «in officio officiando» (23).

(21) Sobre este particular véase mi estudio «Notas para el estudio de la difusión del castellano en Filipinas. La situación de la provincia de la Pampanga en la segunda mitad del siglo XvIII", en Homenaje a Lourdes DiazTrechuelo, Córdoba, Publicaciones del Monte de Piedad y Caja de Ahorros, 1991, págs. 61-75. En especial lo referido a la situación en que se encontraban las «élites" locales.

(22) Auto sobre procesiones de Semana Santa, Apálit, 18 de enero de 1776 , "Testimonio completo", AGI, Filipinas, 653.

(23) Véase el esquema "Relación de párrocos visitados", incorporado al final del trabajo.

R. I., 1996, n. 206 
La presencia de estos regulares al frente de las parroquias de San Fernando, México, Santa Ana y San Luis es importante por cuanto no hay que olvidar que las 22 parroquias pampangas habían sido administradas hasta octubre de 1771, momento de su expulsión, por la Orden Religiosa a la que pertenecían. De hecho, Fray Manuel Soler, Fray Manuel Serradel, Fray Domingo Belveser y Fray José Joaquín Sales, servían sus ministerios desde cinco años atrás, es decir, desde la remoción de sus hermanos de hábito, aunque ahora desempeñaban su tarea «bajo las solemnidades que demanda el derecho». Sólo el párroco de Santa Ana, Fray José Sales, había sucedido a otro religioso, Fray Mariano Alafont.

La razón que explica la presencia de estos religiosos en la Pampanga es su acatamiento al Real Patronato y a la Visita Diocesana que estaba empeñado en imponer el arzobispo Sancho y el gobernador de las islas Simón de Anda y Salazar, a los que se opuso frontalmente la Orden de San Agustín y las demás corporaciones religiosas de las islas.

En realidad, fueron cinco los religiosos que expresaron su disconformidad con la actitud de su Orden ante la Visita y el Patronato y que solicitaron y obtuvieron el real auxilio, reconociendo estar amedrentados por las amenazas de sus hermanos de hábito. A cuatro de ellos (Fray Manuel Soler, párroco de Santa Rita; Fray Domingo Belveser, párroco de San José y Palusapis; Fray Manuel Serradel, párroco de México, y Fray José Joaquín Sales, párroco de Minalín) los encontramos en 1776 en la Pampanga, aunque sirviendo otras parroquias. El quinto, Fray Vicente Pérez, falleció mientras se realizaban los trámites dè remoción. Muy elogiado por las autoridades civiles y por el arzobispo, sufrió durísimas críticas por parte de sus hermanos de hábito que no dudaron en llamarle «el Judas de la Provincia» (24).

(24) «Diligencias de remoción de los doctrineros agustinos calzados de la provincia de la Pampanga», AGI, Filipinas, 1042, fols. 64 y 65. Fray Manuel Serradel nació en Carbet (Valencia), llegó a Filipinas en 1752 donde trabajó en Carranglán e Ilocos. Murió en Gapán en 1790. De fray Manuel Soler sabemos que era natural de Teruel y profesó en el convento de Valencia (1758). Llegó a las islas en 1763 y trabajó en la Pampanya. Murió en San Fernando en 1781. Fray José Sales era natural de Lérida. Profesó en Valladolid y fue destinado a Filipinas en 1754. Fue Definidor de su Provincia y 
Por lo que respecta a los Padres Sales, Soler y Belveser, en el año 1776 los encontramos sirviendo las parroquias de Santa Ana, San Fernando y San Luis, respectivamente. Fray Manuel Serradel fue el único que permaneció en la misma parroquia que había administrado antes de producirse la remoción.

También se extendió la protección real a Fray Mariano Alafont, aun cuando éste la solicitó una vez concluida la secularización de las doctrinas pampangas. Llegado a la provincia con un encargo de su Provincial, remitió desde San Fernando una carta al gobernador expresando su disconformidad con la actitud mantenida por el Orden en materia de Visita y Patronato y su deseo de permanecer en la Pampanga dedicado a la cura de almas (25).

La respuesta llegó tres días más tarde: el gobernador aceptó el reconocimiento del Patronato y la Visita por parte del solicitante y se le colocó bajo la real protección. El alcalde mayor fue encargado de velar por que ésta fuera efectiva, y para garantizar este extremo se envió una carta de ruego y encargo al Provincial de agustinos, Padre José Victoria (26).

Solamente quedaba determinar qué parroquia se le confiaría, decisión que incumbía al arzobispo. Este con rápidez comunicó al gobernador que había dado orden al Vicario foráneo de la provincia para que dispusiera que le fuera entregado con carácter interino el curato de Santa Ana. La toma de posesión

trabajó en la Pampangà. Descubrió un complot para asesinar al después gobernador Anda y Salazar, durante los años de la invasión inglesa de las islas. Murió en Santa Ana en 1789.

P. M. MERINO, Agustinos evangelizadores de Filipinas (1565-1965), Madrid, 1965, págs. 492, 67 y 134 .

(25) Fray Mariano Alafont al gobernador, San Fernando, 23 de enero de 1772, AGI, Filipinas, 1042. La carta fue remitida acompañada de una del alcalde mayor, fechada en Bacollor, a 24 de enero del mismo año. Se encuentra en el mismo legajo.

(26) Decreto del gobernador, Manila, 27 de enero de 1772, AGI, Filipinas, 1042. El decreto por el que estas resoluciones fueron dadas a conocer al alcalde mayor tiene la misma fecha y se encuentra en el mismo legajo, entre los documentos referentes a las diligencias de expulsión, fols. 79-80. La noticia de que gozaba de la real protección le fue comunicada por el alcalde mayor en el pueblo de San Fernando el día 9 de febrero.

La carta remitida al Provincial tiene igual fecha que el decreto. Se encuentra en AGI, Filipinas, 1039.

R. I., 1996, n.o 206 
tuvo lugar pocos días mas tarde, en presencia del citado Vicario y del alcalde mayor.

La razón que llevó al Padre Alafont a manifestarse en contra de la actitud mantenida por la jerarquía de su Orden no es clara. Según él mismo confiesa, es el convencimiento de que ésta era jurídicamente equivocada, y el deseo de ejercer la cura de almas en la Pampanga, donde ya anteriormente lo había hecho, lo que le empujó a ello. Sin embargo, otros miembros de su orden denunciaron que era el deseo de vivir libre del sometimiento debido a sus superiores lo que explicaba la actitud de este religioso de fuerte temperamento. Desde esta perspectiva, su viaje a la Pampanga pudo convencerle de las ventajas que le reportaría pasarse al bando de los partidarios del arzobispo. Lo que es evidente es que cualesquiera que fueran sus motivaciones, consiguió su objetivo y pasó a ocupar la parroquia del pueblo de Santa Ana, y, más tarde, la de San Fernando, donde murió años más tarde (27).

El hecho de que estos religiosos fueran acogidos bajo la real protección y se prohibiera a su Provincial adoptar cualquier medida que pudiera perturbarles, molestó profundamente a la Orden, ya que suponía sustraer algunos de sus súbditos de la debida obediciencia a sus prelados.

El Real Decreto de 25 de agosto de 1774 y la Real Cédula de 9 de noviembre del mismo año dispusieron que estos cinco religiosos fueran restituidos a la jurisdicción de su Provincial, a fin de que se les sustanciaran las causas pertinentes. Al mismo tiempo se recordaba a éste que debía proceder «con la moderación propia de su estado religioso y con arreglo a lo que previenen las leyes y constituciones de su Orden» (28).

El problema, del que no he encontrado más rastro en los

(27) Fray Mariano Alafont era natural de Valencia. Profesó siendo ya sacerdote en 1751 y llegó a Filipinas al año siguiente, donde ejerció durante algún tiempo la cátedra de Teología. Castro dice de él que era "de vivo ingenio y muy leído en materia de cánones e Historia eclesiástica». Fue destinado a la administración de doctrinas en la Pampanga, donde permaneció durante veinte años. Fue Prior de Manila, Vicario Provincial y dos veces Definidor.

A. M. CASTRo, Misioneros agustinos en el Extremo Oriente (1565-1780), Madrid, 1954, págs. 242-243. P. M. MeRINo, Opus cit., pág. 471.

(28) Real Cédula, San Lorenzo, 9 de noviembre de 1774, AGI, Filipinas, 1027

R. I., 1996, n.o 206 
documentos, debió quedar solventado con la llegada de la citada Real Cédula a las islas. A partir de este momento, todas las Ordenes religiosas acataron la Visita y el Patronato, aunque recoletos y franciscanos mostraron su desagrado.

Los dieciocho sacerdotes que administraban las restantes parroquias pampangas eran miembros del clero secular indígena, muy escaso y extradordinariamente mal visto en las islas. Tan sólo el párroco de Guagua, don Juan Nepomuceno Mixares, era mestizo de español; ocho eran pampangos (Bacolor, Magalang, Gapán, Macabebe, San Simón, Apalit, Minalín y Lubao), seis tagalos (Betis, Santa Rita, Tarlac, Santor, Palusapis y San Miguel), y dos mestizos de sangley (Arayat y Candava).

Las edades de estos sacerdotes oscilan entre los 26 de los más jóvenes (Candava y San Simón) y los 54 (Magalang), aunque la mayoría están entre los 30 y los 40 (un total de 11). Seis tienen entre 26 y 29 y sólo uno ha traspasado la barrera de los cincuenta. Se trata en definitiva de sacerdotes jóvenes, muy probablemente ordenados por el propio arzobispo, es decir, de las primeras promociones salidas del Seminario Conciliar que el metropolitano había erigido en el antiguo Colegio de la Compañía de Manila, bajo el nombre de San Carlos.

De trece de ellos sabemos que tenían el grado de bachiller y de otro (el párroco de Minalín) que era doctor. De los demás no se indica otra cosa que su suficiencia para desempeñar el oficio de párroco, y su grado de conocimiento de la lengua pampanga.

En este punto, sin embargo, existen matices. Así, de don Manuel Francisco Tubil, párroco de Macabebe desde hacía tres años, dicen los documentos que era «indio pampango, doctor, graduado en sagrada teología, hábil, de buena vida y costumbres y muy exacto en el cumplimiento de su ministerio" (29). Sin embargo, de don Juan Nepomuceno Mijares, párroco de Guagua desde hacía año y siete meses, sólo se dice que es «bastantemente instruido y exacto en cumplimiento de su ministerio", aunque más adelante se asegura que mandó labrar alhajas de plata y vasos sagrados, pagándolos de su peculio, y que donó dinero que le debía a él la iglesia (30).

(29) Informe sobre el párroco de Minalín, "Testimonio", fol. 5.

(30) Informe sobre el párroco de Guagua, "Testimonio", fol. 6.

R. I., 1996, n.० 206 
En general, son poco detalladas las referencias a la cualificación y comportamiento de los párrocos. Abundan expresiones como «suficiente para este ministerio» (Sexmoán), «bastante hábil» (Santa Rita), «instruido y aplicado en su ministerio» (Magalang y Palusapis), «hábil y exacto en su ministerio» (Arayat, Santor y San Simón).

Cuando el párroco no es natural de la provincia, se tiene buen cuidado de indicar su suficiencia en el idioma pampango. En opinión del arzobispo todos satisfacían este requisito.

En realidad, nueve de los veintidós párrocos que ocupaban en propiedad las parroquias pampangas formaron parte de la lista de curas interinos destinados a esta provincia tras la expulsión de los doctrineros agustinos calzados y la consiguiente secularización de los ministerios.

De tres de ellos tenemos los informes redactados por los agustinos calzados de la provincia a los que sustituyeron después de su expulsión. Se trata de los actuales párrocos de Betis, Tarlac y San Miguel. Del primero, al que le fue encomendado con carácter interino el pueblo de Santor y Bongabón, el Padre fray Manuel Guareña afirma que «no sabe la lengua pampanga, sino tal cual término, la lengua castellana mal hablada, y de latín, según lo ví muy poco» (31).

Lo mismo sucede con don Lorenzo Malaca, párroco de San Miguel de Mayumú y anteriormente de Minalín, del que también se afirma su ignorancia del idioma de aquella provincia. El caso más llamativo es el del párroco de Tarlac, y anteriormente de Santa Ana, don Diego Gutiérrez, de quien se dice que "no sabía la lengua pampanga" y que era "sumamente corto en la obligación perteneciente al párroco y cura de almas» (32). 'En esta materia tan delicada, si damos crédito a las palabras de los doctrineros agustinos, es forzoso concluir que o bien los curas puestos por el arzobispo en las parroquias pampangas habían hecho un considerable esfuerzo por

(31) Informe sobre el párroco de Betis, declaración jurada de fray Manuel de la Guareña, Convento de San Pablo de Manila, 7 de diciembre de 1771, AGI, Filipinas, 1039, fol. 9-10.

(32) Informe sobre el párroco de Tarlac, declaración jurada de fray Matías Octavio ante el Secretario de la Provincia del Santísimo Nombre de Jesús, fray Santiago Tobar, Convento de San Pablo de Manila, 11 de diciembre de 1771, AGI, Filipinas, 1039, fol. 6v. 
alcanzar el nivel que exigía el correcto desempeño de su cargo, o la administración espiritual en la provincia dejaba mucho que desear.

La gestión de todos ellos al frente de sus parroquias fue aprobada sin problemas, únicamente se obligó al párroco de Bacolor, don Juan Carpio, a devolver unas cantidades de dinero que había gastado sin autorización.

En otro orden de cosas, el arzobispo nombró tres coadjutores; uno para aliviar de su carga al párroco de Apalit, y otros dos para asistir al de Gapán, cuya enfermedad le había llevado a solicitar la renuncia al curato.

El arzobispo se mostró satisfecho con la labor desarrollada por los párrocos, sobre los cuales las pesquisas secretas no arrojaron ningún borrón. Sin embargo, les dirigió continuamente exhortaciones para que perseveraran en su esfuerzo por atender debidamente a sus feligreses, al tiempo que les recordaba sus obligaciones. Así, insistió en que no debían ingerirse en los nombramientos de maestro de escuela, por corresponder esta decisión a los alcaldes mayores. Pero les recordó que era obligación suya vigilar el progreso de los niños, de lo que debían dar puntual información a los presidentes de la provincia que, a su vez, mantendrían enterado al metropolitano.

Asimismo insistió en que, en el caso de que hubiera algún feligrés enfermo de cierta consideración, debían administrarle los sacramentos en su casa y no obligarle a que se desplazara al templo para poder recibirlos. Ordenó, para preservar el secreto de las confesiones, que todos los párrocos hicieran doblar las rejillas de los confesionarios, deficiencia que había observado en el transcurso de su inspección. Durante ésta también había dispuesto que se dejara de emplear el papel de China para los libros parroquiales, y que en su lugar se empleara papel más fuerte, «de Europa».

Finalmente, resulta muy significativo el que recordara a los párrocos que en las homilías debían alternar la explicación de la doctrina cristiana en castellano y en la lengua del país. Esto deja ver claramente que el castellano no era, ni mucho menos, conocido de la mayor parte de la población, como en otro documento afirmaba el arzobispo.

La primera de las conclusiones que se deben extraer es que, contrariamente a lo defendido con denuedo por los religiosos, 
el ejercicio de la cura de almas por parte de los regulares era perfectamente compatible con el ejercicio de la Visita por parte de los ordinarios, siempre que ambas autoridades respetaran los ámbitos de acción que les eran propios.

La visita de 1776 se realizó una vez que las Ordenes Religiosas se habían sometido finalmente a la autoridad de los Ordinarios, pero sus reticencias y suspicacias hacia éstos no habían desaparecido. Consciente de ello, el arzobispo limitó escrupulosamente su inspección a la actuación de los religiosos «in officio officiando", y en este punto quedó totalmente satisfecho.

Las fuentes críticas vertidas sobre las rápidas ordenaciones realizadas por el arzobispo, y sobre la cualificación moral e intelectual del clero secular indígena se adivinan gravitando sobre esta visita. Así lo denuncia su insistencia en dejar sentada la capacidad y el buen hacer de los párrocos de la Pampanga, también las continuas exhortaciones que les dirigió durante y después de la visita, y el establecimiento de la nueva división eclesiástica de la provincia. 


\section{APÉNDICES}

1. RELACIÓN DE PÁRROCOS VISITADOS

\begin{tabular}{|c|c|c|}
\hline & $\begin{array}{l}\text { Destino } \\
\text { en } 1776\end{array}$ & $\begin{array}{l}\text { Destino } \\
\text { en } 1771\end{array}$ \\
\hline Br. D. Julián Galang (36) & Macabebe & Bacolor \\
\hline Dr. D. Manuel Fco. Tubil (30) & Minalín & \\
\hline Br. D. Juan Nepomuceno Mijares (28) & Guagua & \\
\hline D. Juan Cabrera Oliveros (28) & Sexmoán & \\
\hline D. Ceferino Aguas (29) & Lubao & \\
\hline Br. D. Juan Roque del Castillo (38) & Betis & Santor \\
\hline Br. D. Juan Carpio (33) & Bacolor & Guagua \\
\hline Br. D. Vicente Eustaquio (30) & Santa Rita & El mismo \\
\hline Fr. Manuel Soler & San Fernando & \\
\hline Fr. Manuel Sarradel (50) & México & \\
\hline Br. D. Manuel Clemente (54) & Magalang & \\
\hline D. Diego Gutiérrez (33) & Tarlac & Santa Ana \\
\hline Fr. José Sales & Santa Ana & \\
\hline Br. D. Remigio Boyson (28) & Arayat & \\
\hline Br. D. Jerónimo Augas (32) & Gapán & México \\
\hline Br. D. Andrés Vivar (39) & Santor & \\
\hline Br. D. José Lajón (38) & San José & El mismo \\
\hline Br. D. Bonifacio Narciso de Mendoza (26) & Candava & \\
\hline Br. D. Lorenzo Malaca (31) & San Miguel & Minalín \\
\hline Fr. Domingo Tomás Belveser & San Luis & \\
\hline Br. D. Eugenio Octong (26) & San Simón & \\
\hline D. Antonio Ubaldo Bondoc (32) & Apalit & \\
\hline
\end{tabular}

(*) La cifra entre paréntesis corresponde a la edad. 
2. Extracto de habitantes de la PRovincia de la Pampanga (1776)

\begin{tabular}{lcccc}
\hline \multicolumn{1}{c}{ Pueblos } & $\begin{array}{c}\text { Europeos } y \\
\text { mestizos de } \\
\text { español }\end{array}$ & Indios & $\begin{array}{c}\text { Mestizos } \\
\text { de } \\
\text { sangley }\end{array}$ & Total \\
\hline Bacolor & 132 & 4.210 & 2.244 & 6.586 \\
San Fernando & - & 2.052 & 2.243 & 4.295 \\
México & 13 & 2.467 & 1.920 & 4.400 \\
Santa Ana & 2 & 1.966 & 523 & 2.491 \\
San Luis & - & 2.244 & - & 2.244 \\
Guagua & 51 & 2.419 & 936 & 3.406 \\
Betis & 15 & 1.207 & 696 & 1.918 \\
Lubao & 36 & 2.667 & 52 & 2.755 \\
Santa Rita & 21 & 1.246 & 296 & 1.563 \\
Sexmoan & - & 1.476 & 17 & 1.493 \\
Macabebe & 49 & 4.865 & 384 & 5.298 \\
Minalín & 27 & 3.466 & 858 & 4.351 \\
San Simón & 8 & 1.825 & 90 & 1.923 \\
Arayat & 18 & 2.040 & 39 & 2.097 \\
Candava & - & 3.774 & 63 & 3.889 \\
Gapang & - & 3.116 & 1.347 & 4.463 \\
Apalit & 41 & 2.340 & 69 & 2.450 \\
Magalang & - & 937 & - & 937 \\
San Miguel & 5 & 1.404 & 124 & 1.533 \\
Santor & 7 & 1.550 & 85 & 1.642 \\
Tarlac & - & 2.415 & - & 2.415 \\
Palusapis & - & 1.904 & - & 1.904 \\
\hline TOTAL & 477 & 51.590 & 11.986 & 64.053 \\
\hline
\end{tabular}

(*) En este extracto se incluyen los niños y párvulos de cada pueblo.

The pastoral visit of inspection to the Philippine province of Pampanga, made by the archbishop of Manila in 1776, was the first such tour of inspection since the violent secularization of the twenty two parishes five years earlier. Based on unpublished sources from the General Archive of the Indies, the study describes the situations of the churches, the working conditions of the priests in the twenty two parishes, and the degree of conversion of the native peoples. 